\title{
Postoperative delirium following cardiac surgery: the incidence, risk factors and outcome
}

\author{
Judita Andrejaitiene ${ }^{1,2^{*}}$, Rimantas Benetis ${ }^{1,2}$, Edmundas Sirvinskas ${ }^{1,2}$ \\ From World Society of Cardiothoracic Surgeons 25th Anniversary Congress, Edinburgh \\ Edinburgh, UK. 19-22 September 2015
}

\section{Background/Introduction}

Postoperative delirium (POD) is a common and serious complication after cardiac surgery and numerous studies have confirmed this in occurrence from $10 \%$ to $60 \%$, patients have an increased risk of developing POD that is associated with poor outcomes.

\section{Aims/Objectives}

The aim of this study was to identify POD incidence, potential risk factors and to evaluate clinical outcome.

\section{Method}

A single-centre cohort of 292 patients undergoing elective cardiac surgery were prospectively enrolled.

\section{Results}

The incidence of POD was $27.74 \%$. The analysis showed that POD prolonged the length of the ICU stay $5.8( \pm 2.89)$ vs $3.86( \pm 1.91)$ days, $\mathrm{p}<0.001$, patients after POD more frequent was required re-intubation (OR: 13.169; 95\% CI 1.456-119.087, $\mathrm{p}=0.022$ ) and had had the prolonged length of the postoperative hospital stay $>10$ days (OR: 2.060; 95\% CI 1.226-3.460, $\mathrm{p}=0.006$ ). Multivariate analysis remained as an independent predictors for POD: age $>70$ yr (OR: 2.227; 95\% CI 1.325-3.742, $\mathrm{p}=0.003$ ), ejection fraction < 42\% (OR: 2.398; 95\% CI 1.397-4.117, $\mathrm{p}=0.002$ ), length of stay in the hospital before surgery $>6$ days (OR: 1.840; 95\% CI 1.064-3.180, $\mathrm{p}=0.029$ ), combined valve repair and CABG surgery (OR: 2.083; 95\% CI 1.153-3.761, $\mathrm{p}=0.015)$, duration of $\mathrm{CPB}>86 \mathrm{~min}$ (OR: $2.068 ; 95 \% \mathrm{CI}$ 1.182-3.618, $\mathrm{p}=0.009$ ) and postoperative atrial fibrillation (OR: 2.244; 95\% CI 1.158-4.347, $\mathrm{p}=0.007$ ).

Institute of Cardiology, Lithuanian University of Health Sciences, Kaunas, LT50009, Lithuania

Full list of author information is available at the end of the article

\section{Discussion/Conclusion}

Our current analysis suggests that POD is a frequent complication and worsen patient outcome following cardiac surgery. Many factors cannot be changed or avoided but some can be modified and it depends from us: if to shorten the length of stay in the hospital before surgery $<6$ days, it may reduce the number of patients who develop POD. By the way, a large prospective randomised study in this regard is needed.

\section{Authors' details}

'Institute of Cardiology, Lithuanian University of Health Sciences, Kaunas, LT50009, Lithuania. ${ }^{2}$ Department of Cardiac, Thoracic and Vascular Surgery, Hospital of Lithuanian University of Health Sciences, Kaunas Clinics, Kaunas, LT-50009, Lithuania.

Published: 16 December 2015

doi:10.1186/1749-8090-10-S1-A298

Cite this article as: Andrejaitiene et al: Postoperative delirium following cardiac surgery: the incidence, risk factors and outcome. Journal of Cardiothoracic Surgery 2015 10(Suppl 1):A298.

Submit your next manuscript to BioMed Central and take full advantage of:

- Convenient online submission

- Thorough peer review

- No space constraints or color figure charges

- Immediate publication on acceptance

- Inclusion in PubMed, CAS, Scopus and Google Scholar

- Research which is freely available for redistribution 